\title{
EL DESAPRENDER EL PENSAMIENTO JURÍDICO COMO ACCESO A LA LEY MODELO DE CONCILIACIÓN COMERCIAL INTERNACIONAL
}

\author{
Luis Miguel DÍAZ*
}

RESUMEN: En la primera parte se cuestiona la eficacia de los sistemas judiciales para la solución de conflictos. Se requiere "desaprender" el pensamiento jurídico (olvidar lo que se había aprendido) para aprender a ser un solucionador de conflictos. Es decir, colocarse en el lado del error para aprender el acierto. En la segunda parte se presenta la Ley Modelo sobre Conciliación Comercial Internacional de la Comisión de las Naciones Unidas para el Derecho Mercantil Internacional (CNUDMI). Esta ley se inspiró en la creencia de que los protagonistas de conflictos legales pueden resolverlos por sí mismos. Finaliza con una propuesta para incorporar los principios básicos de la ley modelo en la legislación mexicana.

ABSTRACT: In the first part of the article, the author questions the effectuality of achieving conflict resolution through judicial systems. One must "unlearn" traditional legal thinking (i.e., forget what one has learned) in order to learn to become an effective conflict solver. In other words, one must place oneself on the error side in order to learn the right side. In the second part of the article, the author introduces the Model Law on International Commercial Conciliation adopted by the United Nations Commission on International Trade Law (Uncitral). This model law was inspired by the belief that the protagonists in legal conflicts can solve them by themselves. The author concludes by proposing how Mexico may incorporate the basic Uncitral model law principles into its domestic law.

RÈSUMÈ: Dans la première partie, l'autour met en question l'efficacité pour le règlement des différends par les systèmes juridiques. If faut «désapprendre»le pensée juridique traditionnel (donc, il faut qu'on oublie ce qu'on a appris) afin d'apprendre les habilités d'un régleur efficace des différends. C'est á dire, il faut se placer dans le côté de l'erreur afin d'apprendre le côté juste. Dans la deuxième partie, l'auteur expose la Loi type sur la conciliation commerciale internationale adoptée par de la Commission des Nations Unies pour le droit commercial international (CNUDCI). L'inspiration de celle-là c'étais l'idée que les protagonistes dans les différends peuvent en régler eux-mêmes. L'auteur conclue en posant comment est-ce que le Mexique peut incorporer dans le droit mexicain les principes fondamentaux de la Loi type de la CNUDCI.

* El autor es abogado con mención honorífica de la UNAM, maestro en derecho y doctor en ciencias jurídicas de Harvard Law School. Es presidente del Centro Interdisciplinario para el Manejo de Conflictos, A. C. www.solucionnegociada.com 
SUMARIO: I. Introducción. II. La subjetividad humana y la ineficiencia creciente de los sistemas judiciales. III. El método de desaprender. IV. Desaprender el pensamiento jurídico. V. ¿Cómo se aprende a ser negociador o mediador? VI. Actualidad de la mediación-conciliación. VII. Contexto de la ley modelo. VIII. Estructura de la ley modelo. IX. Texto de la Ley Modelo sobre Conciliación Comercial Internacional. X. Propuesta para incorporar los principios de la ley modelo a la legislación mexicana.

\section{INTRODUCCIÓN}

El propósito principal de este artículo es presentar al lector jurista la Ley Modelo de Conciliación Comercial Internacional de las Naciones Unidas. ${ }^{1}$ Sin embargo, antes de hacer dicha presentación me permitiré recurrir a lenguajes no jurídicos para compartir algunas reflexiones sobre el factor humano existente detrás del interés de promover la conciliación para que las personas arreglen sus conflictos por sí mismas en lugar de que los sometan a la decisión de terceros, sean estos tribunales judiciales, autoridades administrativas o árbitros.

\section{LA SUBJETIVIDAD HUMANA Y LA INEFICIENCIA CRECIENTE DE LOS SISTEMAS JUDICIALES}

El sistema judicial para la solución de algunos conflictos por los tribunales de derecho parece ineficiente. ${ }^{2}$ ¿Por qué? Una hipótesis explicativa es que las leyes sobre como deben funcionar los tribunales de derecho presuponen humanos inexistentes. Esto es, ciudadanos ideales y jueces sin historia, emociones y pensamientos propios. Se supone que los jueces no tienen historia personal y por ello sus decisiones son imparciales.

1 Texto en www.uncitral.org

2 En las últimas décadas en prácticamente todo el planeta se ha puesto en duda la efectividad de los sistemas judiciales tradicionales para decidir controversias legales. Véase Cappelletti, Mauro (ed.), Access to Justice, 4 vols. 1978-1979, Sijthoff Noordhoff International Publishers, The Netherlands, 1980. Más reciente y en relación a México, el documento E/CN.4/2002/72/Add.1, 24 de enero 2002, que contiene Informe sobre la misión cumplida en México, presentado al Consejo Económico y Social de la ONU sobre Los Derechos Civiles y Políticos, en particular las cuestiones relacionadas con: la independencia del Poder Judicial, la administración de justicia, la impunidad. 
Esta percepción tuvo sentido cuando se asumía que había dos tipos de seres humanos, unos nacidos para gobernar y otros para obedecer, tan de moda en la época de Sócrates, Aristóteles y sus amigos. Hoy sustentamos nuestra vida política en el dogma de que todos somos iguales para efectos jurídicos.

Sin embargo, si bien ya no se acepta que haya humanos superiores e inferiores, permanece un sincretismo. Se supone que los jueces son imparciales y pueden conocer mundos objetivos. Los ciudadanos comunes no. Estas características atribuidas a los juzgadores es una construcción epistemológica necesaria para dar coherencia al orden jurídico como un sistema imparcial para resolver disputas. Sin embargo esta premisa no tiene nada que ver con la manera real en que cualquier humano, juzgador y ciudadano común, piensa, siente y se comporta. Todos los puntos de vista del ser humano son subjetivos y prejuiciados.

¿Qué se puede hacer? Si no hay humanos imparciales, ¿qué se puede hacer para diseñar sistemas adecuados para resolver conflictos que estén libres del prejuicio personal? Parece que se requiere un cambio de enfoque.

Parafraseando a Einstein, uno puede reformular los problemas añejos. Así, en vez de insistir en lo que no funciona, o de buscar humanos irreales que carezcan de pensamientos y sentimientos individuales, el sistema legal debería promover la comunicación personal entre las partes que resuelvan sus conflictos. Cuando las partes no se pongan de acuerdo, habría que facilitar que recurran a una tercera persona que facilite la negociación entre las partes para que ellas alcancen una solución aceptable a su problema.

Se requiere rescatar el aprecio propio para resolver problemas y se requiere desaprender nuestros prejuicios sobre el derecho, que es el espacio de problemas. Hay que aprender a negociar y a mediar que es el espacio de la solución. Hay que diseñar un sistema para resolver conflictos sin autoridades.

\section{EL MÉTODO DE DESAPRENDER}

Esta hipótesis sostiene que el punto de partida para aprender es colocarse en el lado del error para aprender el acierto. El ser humano ha aprendido ciertas regularidades del universo a través del ciclo experiencia-expectativa-experiencia. Al romperse dicho ciclo se enfrenta un 
error, pues la experiencia o la expectativa previstas no ocurren. Entonces es necesario un nuevo aprendizaje para ocupar el espacio de la expectativa o de la experiencia frustradas. Con esta misma hipótesis explicativa de cómo el ser humano aprendió desaprendiendo ciertas regularidades del universo, se propone como el más seguro punto de partida el error para luego ocupar, en su lugar, el acierto.

El método de desaprender ya aparecía en la obra de Antístenes, el filósofo ateniense fundador de la escuela cínica. Su primera lección era que ignorar, no era menos importante que saber. Comenzaba su enseñanza con el desengaño. Él enseñaba a sus alumnos primerizos que desaprendieran los errores para mejor aprender después los aciertos. ${ }^{3}$

Wittgenstein, el pensador más original del siglo XX, compartió la misma opinión que el maestro griego. ${ }^{4}$ En sus comentarios a Frazer señala:

Hay que empezar por el error y conducirlo a la verdad. Esto es, hay que descubrir la fuente del error, pues de otra manera no nos sirve de nada oír la verdad. Ella no puede penetrar cuando otra cosa toma su lugar. Para convencer a alguien de la verdad no basta constatarla, sino que es preciso encontrar el camino que conduce del error hacia la verdad. ${ }^{5}$

Ciorán, el filósofo de la lucidez, escribió en el mismo sentido: "El no saber es la gran equivocación que sirve de base a todas nuestras verdades; el no saber es más antiguo y más poderoso que todos los dioses reunidos". 6

No hay que subestimar lo muy difícil que es desaprender. Wittgenstein señala en sus últimos escritos sobre la filosofía de la psicología, que no hay nada más difícil que mirar a los conceptos sin prejuicios, pues los prejuicios son una forma de entender al mundo. ${ }^{7}$

3 Gracián, Baltasar, El hombre en su perfección. Saber para vivir, 1a. reimpr., México, Planeta, 1997.

4 Wittgenstein, Ludwig, Tractatus Logico-Philosophicus, Barcelona, Altaya, 1988 (México, UNAM, Instituto de Investigaciones Filosóficas, 1994), p. 124.

5 Wittgenstein, Ludwig, Comentarios sobre La Rama Dorada, ed. de Rush Rhees y trad. de Javier Esquivel, México, UNAM, 1985, p. 9.

6 Ciorán, E. M., Del inconveniente de haber nacido, Madrid, Taurus, 1982, pp. 20 y 21.

7 Wittgenstein, Ludwig, Last Writings on the philosophy of psychology, Volume I, Preliminary Studies for Part II of Philosophical Investigations, University of Chicago Press, 1990, p. 3 E. 


\section{DESAPRENDER EL PENSAMIENTO JURÍDICO}

Cuando existe un conflicto legal, el funcionario gubernamental, el ciudadano común, el empresario, ejecutivo, el comerciante o el inversionista piensan en recurrir o contratar a un abogado para que lleve el asunto ante una autoridad que decida (juez o árbitro). Hay que desaprender este prejuicio.

La realidad común es que las partes de los procesos jurisdiccionales no tienen control sobre el proceso ni sobre el resultado. Hay gran incertidumbre. Este sistema generalmente deja insatisfechas a una o ambas partes, genera angustia y cuesta mucho.

Por otra parte, el derecho procesal es la guerra disfrazada de derecho. A manera de ejemplo véanse algunos términos bélicos y sus equivalentes jurídicos:

Los contendientes requieren un ejército (despachos de abogados); declaración de guerra (demanda); guerra preventiva (medidas precautorias); un general que comande al ejército (abogado principal); un campo de batalla (autoridades con jurisdicción); dominio de reglas de ofensa y defensa (derecho procesal); conocimiento de la efectividad de las armas (deberes y derechos); fijar estrategias (escenarios de instancias procésales); uso de artillería (hechos); manejo del material bélico (argumentos legales); espacios de consulta (juntas de avenencia); municiones (dinero); declaración de victoria (sentencia favorable).

Esta lista es sólo una muestra de la simetría entre el modo de pensar en la guerra y en el procedimiento jurisdiccional. Lo legal es el espacio del problema. El procedimiento legal impide la comunicación directa entre las partes. Hay que desaprender pensamientos implícitos y explícitos sobre el derecho que impiden la solución de conflictos.

En vista de la unicidad y poca originalidad de los seres humanos, me parece que lo mejor para resolver conflictos es la comunicación directa o facilitada por una tercera persona. Lo peor es impedir la comunicación, como lo hace el derecho procesal. Por todo lo anterior, es necesario desaprender el derecho para aprender a ser un negociador o mediador. 


\section{V. ¿CÓMO SE APRENDE A SER NEGOCIADOR O MEDIADOR?}

Una de las primeras interacciones del ser humano es negociar y mediar para sobrevivir. Negocian madre y bebé el acceso a la leche materna. Negociar es lo contrario a imponer sucesos, a utilizar la fuerza, a recurrir a la violencia o a pleitear interpretaciones. Se media y se negocia en la vida de familia, en transacciones comerciales y en las relaciones de trabajo. En centros financieros y clubes deportivos. En el medio más modesto y en las grandes decisiones políticas.

Freud escribió en 1926 el artículo “¿Pueden los legos ejercer el psicoanálisis? Diálogos con un juez imparcial", ${ }^{8}$ para abogar por su amigo Theodor Reik, miembro prominente de la Sociedad Psicoanalítica de Viena. Reik no era médico y se le acusaba de violar una ley contra el curanderismo que declaraba ilegal el ejercicio del psicoanálisis por alguien que no fuera médico.

En su escrito Freud sostenía un diálogo imaginario con un juez imparcial al que trataba de convencer de que todos podemos juzgar tesis psicológicas, ya que no requerimos de conocimientos especializados. Dicha actividad no está reservada a los especialistas, como sí lo son el ejercicio de otras disciplinas como la medicina, la contabilidad, la física, la química.

En el diálogo con el juez, Freud cita el caso de una quinceañera que solicitaba un empleo consistente en cuidar a una niña, a quien se le preguntó cuál era su experiencia como niñera. Contestó ella que sí tenía, que no hacía mucho tiempo había sido una niña pequeña.

Percepción similar se encuentra en el título de un libro: Todo lo que realmente necesitaba saber lo aprendi en el año preescolar. ${ }^{9} \mathrm{El}$ autor expone de un modo muy sencillo que las reglas fundamentales para la convivencia se aprenden en los primeros años de socialización del ser humano.

En consecuencia, mediar o negociar es algo en que todos hemos participado, participamos y seguiremos participando. En nuestra propia biología se encuentra las aptitudes para interactuar con los demás. Todos te-

8 Freud, Sigmund, The Question of Lay Analysis, Standard 20, 179; PFL, 15. También en Obras completas, trad. del alemán por José L. Etcheverry, ord., com. y notas de James Strachey y Anna Freud, Buenos Aires, Amorrortu editores, 1979, vol. 20 (1925-26).

9 Fulghum, Robert, All I really need to know I learned in kindergarten, New York, Villard Books. 
nemos en mayor o menor grado tres tipos de inteligencias idóneas para resolver nuestros conflictos con los demás. Estas tres inteligencias son la inteligencia instintiva, la intuitiva y la racional. ${ }^{10}$

Toda generalización sobre mediadores o negociadores o mediar o negociar, debe tener excepciones, puesto que cada cabeza humana y cada situación de negociación son únicas. Por ello parece sin sentido proponer un método de mediación o negociación que en todos los casos y bajo cualquier circunstancia, sea pertinente.

Por lo anterior, en vez de proponer reglas que siempre tendrán excepciones para mediaciones y negociaciones, mi manera de pensar sobre cómo negociar y mediar mejor se sustenta en ser flexible y en desaprender lo que no funciona.

La mediación se sustenta en el uso del lenguaje, por lo que para negociar o mediar el aprender a usar el lenguaje es fundamental. Por ejemplo, una moraleja puede servir para múltiples propósitos en una mediación o negociación. Las moralejas por alguna sin razón o razón no implican una amenaza, captan el interés del oyente, son un modelo de flexibilidad y hacen más memorable la idea expuesta. Para adelantar ideas e intensificar las motivaciones, narrar una moraleja puede ser muy útil. Las moralejas pueden emplearse para formular órdenes veladas. La formulación indirecta puede consistir en variaciones de la entonación en la narración de la moraleja.

Por el mismo hecho de ser indirectas, las moralejas pueden ser utilizadas para eludir la natural resistencia al cambio. Las moralejas sirven también para ofrecer nuevos marcos de referencia de un problema. Las moralejas pueden servir para desensibilizar a una persona respecto de sus temores o para recordarle que recursos tienen para confrontar situaciones.

Por mediar o negociar mejor entiendo la capacidad para utilizar con plenitud los recursos que tiene el cuerpo humano para comunicar a otro que veo, pienso, oigo, siento, huelo, deseo, sueño y espero, a través de palabras y lenguaje corporal. Así, cuando existe un negociador neutral

10 En mi artículo "Privatización de conflictos" (El Foro, t. X, núm. 1, 1997, pp. 55-96) y en mi libro Moralejas para mediar y negociar (Themis, 2004) desarrollo las hipótesis de las tres inteligencias. En mi libro Más Chaplin y menos Platón. Manejo de conflictos desde la sabiduría del cine y las canciones (Santiago, Chile, Cuatro Vientos, 2004) pondero el recurso a imágenes más que a palabras para reconocer las habilidades para negociar. 
que hable de las cualidades y logros de los otros, se facilita el equilibrio de las pasiones.

Un negociador facilitador entre las partes de un conflicto, puede buscar comprensión entre las partes, contextualizar las posiciones, identificar intereses, propiciar procesos, allegar información, y sugerir propuestas de solución. Un facilitador debe poseer la capacidad para comprender las estrategias el modo de pensar y de emocionarse de las partes de un conflicto. O sea, cómo organizan y representan las partes sus experiencias y sus expectativas respecto a la materia del conflicto. El facilitador no debe involucrarse en el contenido del conflicto, pues es la materia sobre la cual las partes deben decidir. El papel del facilitador, como profesional de la comunicación, consiste en descubrir cómo operan los procesos de las partes para tender puentes de comunicación entre ellas y eventualmente, contribuir a generar opciones. El facilitador debe incorporar las representaciones que las partes hacen de sus modelos sobre el conflicto. $\mathrm{Su}$ papel no es introducirlas a los sistemas de valor o creencias propias. La eficacia del facilitador presupone su aceptación de los valores, creencias e integridad de las partes.

Encuentro pertinente algún tipo de asociación entre la labor de un facilitador negociador y la ciencia de la caballería andante, profesada por el ilustre hidalgo don Quijote de la Mancha.

Dicha ciencia encierra en sí todas o las más ciencias del mundo, a causa que de que el que la profesa ha de ser jurisperito...ha de ser teólogo.... ha de ser médico, y principalmente herbolario... ha de ser astrólogo... ha de saber las matemáticas... ha de ser casto en los pensamientos, honesto en las palabras, liberal en las obras, valiente en los hechos, sufrido en los trabajos, caritativo con los menesterosos, y, finalmente mantenedor de la verdad, aunque le cueste la vida defenderla.

Así, la utilidad del método de mediación o negociación y la capacidad para usarlo con flexibilidad la determina cada mediador o negociador en cada caso. El peligro más grande es el de creer que algo, siempre y bajo cualquier circunstancia, es igualmente válido o inválido, eficaz o ineficaz, útil o inútil, bueno o malo, pertinente o impertinente. El punto de partida es que, por alguna razón o sin razón, el cerebro humano registra mejor aquello que aprende a partir de desaprender. Esta hipótesis sustenta la manera de pensar que se propone para mediar y negociar mejor. 
La hipótesis de la negociación y mediación para manejar conflictos descansa en una nueva manera de pensar sobre los conflictos y en tres presupuestos:

a) Que las partes realmente desean una solución satisfactoria a su conflicto.

b) Que las partes prefieren tener opciones para resolver su conflicto, que no tenerlas.

c) Que las partes tengan confianza en el negociador facilitador.

Parece que la verdadera alternativa a los medios judiciales o al arbitraje para la solución de los conflictos, es el recurso al negociador facilitador, cuando la negociación entre las partes no funciona.

\section{ACTUALIDAD DE LA MEDIACIÓN-CONCILIACIÓN}

Cerca del 90\% de los casos, en que las partes de un conflicto toman la negociación para terminar un conflicto, el resultado es una solución negociada satisfactoria para ambas partes. La gran mayoría de las soluciones negociadas se cumplen por las partes.

La conciliación se está convirtiendo en una opción promovida por leyes y tribunales para la solución de controversias en organismos gubernamentales y en los ámbitos comunitario, laboral, familiar y comercial. Esta tendencia se refleja, por ejemplo, en una copiosa literatura. ${ }^{11}$

Simultáneamente, la creciente dificultad de los tribunales judiciales para desahogar los asuntos presentados ante ellos, ha dado pie para la elaboración de legislaciones que propugnen soluciones jurídicas entre las

11 A manera de muestra, Schilling, Mario Tomás, Manual de mediación. Resolución de conflictos, Santiago, Chile, Cuatro Vientos, 2002; Álvarez, Gladys y Highton, Elena, Mediación para resolver conflictos, Buenos Aires, Editorial Ad-Hoc, 1995; Álvarez T., Manuel, Técnicas de negociacion para abogados, Buenos Aires, Abeledo Perrot, 1999; Alzate de Heredia, Ramón, "Cognicion y negociacion: una revisión de la literatura desde la teoría prospectiva", Revista de Psicología Social Aplicada, País Vasco, 1999; Barceló, Portal y Sánchez (coords.), Diversidad étnica y conflicto en América Latina, México, UNAM, 1998; Azar Mansur Cecilia, Mediación y conciliación en México: dos vías alternativas de solución de conflictos a considerar, México, Porrúa, 1993, Breviarios Jurídicos 11; Vinyamata, Camp Eduardo, Aprender mediación, Barcelona, España, Paidós, 1993; Folberg, J. y Taylor, A., Mediación: resolución de conflictos sin litigio, México, Noriega, 1992; Fiarén Guillén, Víctor et al., Justicia y sociedad, figuras extraprocesales de arreglo de conflictos: la conciliación, la mediación y el ombudsman, México, UNAM, 1994. 
partes dentro de las propias jurisdicciones (centros de mediación anexos a tribunales). ${ }^{12}$

La búsqueda de un instrumento internacional para ayudar a los Estados a establecer vías para la solución de las controversias que reduzcan su costo, promuevan un clima cooperativo entre las partes, prevengan futuras disputas y den mayor certeza al comercio internacional fueron algunas razones que detonaron la negociación de la ley modelo.

\section{CONTEXTO DE LA LEY MODELO}

La Ley Modelo en Conciliación Comercial Internacional de las Naciones Unidas ${ }^{13}$ se inspira en la creencia de que los protagonistas de conflictos legales pueden resolverlos por sí mismos y en que un creciente número de conflictos legales parecen no tener soluciones legales.

\section{Negociación de la ley modelo en Naciones Unidas}

En la Comisión de las Naciones Unidas para el Derecho Mercantil Internacional (CNUDMI) ${ }^{14}$ se negoció la Ley Modelo de Conciliación

12 Respecto a México, véase www.mediacionenmexico.org. Este sitio contiene información sobre los avances y el desarrollo de la mediación en 18 estados de la república participantes del Proyecto ABA-USAID de Mediación en México.

13 Texto en www.uncitral.org. La Comisión sobre el Derecho Mercantil Internacional (CUNDMI) ha aprobado las siguientes leyes modelo: Ley Modelo sobre Arbitraje Comercial Internacional (1985), Ley Modelo sobre Transferencias Internacionales de Crédito (1992), Ley Modelo sobre Contratación Pública de Bienes, Obras y Servicios (1994), Ley Modelo sobre Comercio Electrónico (1996), Ley Modelo sobre la Insolvencia Transfronteriza (1997), Ley Modelo sobre las Firmas Electrónicas (2001) y Ley Modelo sobre Conciliación Comercial Internacional (2002).

14 Los miembros de la CNUDMI a partir del 14 de junio 2004, y los años en que expiran sus respectivos mandatos son los siguientes: Algeria (2010), Alemania (2007), Argentina (2007), Australia (2010), Austria (2010) Belarus (2010), Bélgica (2007), Benin (2007), Brasil (2007), Camerún (2007), Canadá (2007), Chile (2007), China (2007), Colombia (2010), Croacia (2007), Ecuador (2010), España (2010), Estados Unidos (2010), Federación Rusa (2007), Fiji (2010), Francia (2007), Gabón (2010), Guatemala (2010), India (2010), Irán (Republica Islámica de) (2010), Irlanda y Gran Bretaña (2007), Israel (2010), Italia (2010), Japón (2007), Jordania (2007), Kenia (2010), Líbano (2010), Lituania (2007), Macedonia (2007), Madagascar (2010), Marruecos (2007), México (2007), Mongolia (2010), Nigeria (2010), Pakistán (2010), Paraguay (2010), Polonia (2010), Qatar (2007), Republica Checa (2010), República de Corea (2007), Ruanda (2007), Serbia y Montenegro (2010), Sierra Leona (2007), Singapur (2007), Sri Lanka (2007), Sudáfrica (2007), Suiza (2007), Swazilandia (2010), Tailandia (2010), Túnez (2007), Turquía (2007), Uganda (2010), Uruguay (2007), Venezuela (2010), Zimbabwe (2010). 
Comercial Internacional entre 2000 y $2002 . .^{15}$ Los resultados de dichas negociaciones fueron el texto de la ley modelo y una guía explicativa de su texto y sus antecedentes. ${ }^{16}$ La guía se elaboró pensando en los órganos del poder ejecutivo y del poder legislativo que se hayan de encargar de efectuar la revisión legislativa en los países interesados. También la información de la guía fue concebida pensando en otros usuarios del texto como empresarios, jueces, abogados en ejercicio y círculos académicos. Este artículo busca de una manera mucho más modesta y breve lo mismo que la guía pero de un modo menos erudito y solemne.

En su 35o. periodo de sesiones el Grupo de Trabajo sobre Arbitraje y Conciliación creado por la Comisión concluyó el examen de las disposiciones y examinó el proyecto de guía. ${ }^{17}$ La Secretaría de la CNUDMI revisó el texto del proyecto de guía para la incorporación al derecho interno y utilización de la ley modelo sobre la base de las deliberaciones del Grupo de Trabajo. El proyecto de ley modelo, junto con el proyecto de guía para su incorporación al derecho interno y utilización, se distribuyó a los Estados miembros y observadores para que formularan comentarios y se sometió al examen y aprobación de la Comisión en su 35o. periodo de sesiones, celebrado en Nueva York del 17 al 28 de junio de 2002 (véase A/CN.9/506, párrafo 13). Los comentarios recibidos se reunieron en el documento A/CN.9/513 y adiciones 1 y 2. La CNUDMI aprobó la ley modelo por consenso el 24 de junio de 2002 (las deliberaciones de la Comisión al respecto figuran en su informe sobre la labor de su 35o. periodo de sesiones).

Durante la preparación de la ley modelo participaron en el debate representantes de unos 90 Estados, 12 organizaciones intergubernamentales y 22 organizaciones internacionales no gubernamentales. ${ }^{18}$ Posteriormente, la Asamblea General aprobó la Resolución en la que recomendó a

15 En su 320. periodo de sesiones, celebrado en 1999, la comisión tuvo a su disposición la nota titulada "Posible labor futura en materia de arbitraje comercial internacional" (A/CN.9/460). La comisión encomendó la labor a uno de sus grupos de trabajo, al que denominó Grupo de Trabajo II (Arbitraje y Conciliación) y decidió que entre los temas prioritarios figurase la labor sobre la conciliación. La ley modelo fue elaborada en el transcurso de cuatro períodos de sesiones del Grupo de Trabajo (32o. a 35o., los informes correspondientes figuran en los documentos A/CN.9/468, A/CN.9/485, A/CN.9/487 y A/CN.9/506).

16 A/CN.9/514.

17 El presidente del Grupo de Trabajo de Uncitral fue el jurista mexicano José María Abascal.

18 Incluyendo, por vez primera, una representación del Comité 2022 del NAFTA sobre Solución de Controversias Privadas Comerciales Internacionales, que incluía un jurista de cada uno de los tres países, Canadá, Estados Unidos y México. 
todos los Estados que consideraran debidamente la posibilidad de incorporar a su derecho interno la ley modelo, ${ }^{19}$ en atención a la conveniencia de uniformar el derecho relativo a los procedimientos de solución de controversias y las necesidades concretas de la práctica comercial internacional en materia de conciliación. ${ }^{20}$

\section{Conciliación en la ley modelo}

En la conciliación la tercera persona asiste a las partes pero ellas controlan el proceso y su resultado. En el arbitraje, el árbitro sigue un procedimiento y decide conforme a reglas jurídicas o en base a principios de equidad, si las partes así lo autorizaron.

El término "conciliación" se utiliza en la ley modelo para designar, en sentido amplio, todo procedimiento por el que una persona o un grupo de personas prestan asistencia a las partes en una controversia para que puedan llegar a una solución amistosa. En la conciliación, el conciliador ayuda a negociar una transacción en que se compaginen las necesidades y los intereses de las partes en la controversia. El tercero neutral no tiene autoridad para imponer a las partes una solución de la controversia.

En muy importante destacar que leyes nacionales y tratados internacionales usan diversos términos como conciliación, mediación, amigable composición, evaluación neutral, dictamen neutral, mini-proceso o expresiones similares pare significar todo procedimiento por el que las partes en una controversia reciben ayuda de un tercero para solucionarla. Todos esos términos representan diversas técnicas y adaptaciones de procedimientos para dirimir controversias que son denominados métodos alternos a los tradicionales de solución de controversias por vía judicial.

En la ley modelo se utiliza el término "conciliación" para englobar a todos esos procedimientos. En la doctrina se hacen distinciones entre esos conceptos en función del método empleado por el tercero o del gra-

19 Croacia, Estados Unidos de América y Hungría ya la incorporaron a sus legislaciones internas. Respecto a Estados Unidos, véase www.nccusl.org/Update/. En este sitio aparece el texto del Acta Uniforme de Mediación (Uniform Mediation Act) adoptada en 2001 y modificada en 2003 para incorporar la referencia a la ley modelo. Quizás por descuido en México no se ha discutido la ley modelo en el Congreso ya que la filosofía de la ley es enteramente compatible con el espíritu democrático actual del país y con sus últimas iniciativas de reformas legales sobre procuración de justicia.

20 Para los testimonios de la preparación de la ley modelo, véase www.uncitral.org bajo el título Travaux Préparatoires y en el Anuario de la CNUDMI. Esta información aparece en los seis idiomas oficiales de las Naciones Unidas (árabe, chino, español, francés, inglés y ruso). 
do en que el tercero interviene en el proceso. En algunos casos, las diversas expresiones parecen más variantes lingüísticas que rasgos singulares del método empleado. En la medida en que una "vía alternativa para la solución de una controversia" tenga como característica que el tercero se limita a ayudar a las partes a dirimir la controversia y de que no puede imponerles una decisión vinculante, dicha vía está comprendida en la ley modelo.

Dado que el conciliador no toma decisiones, no se necesitan garantías procesales como las que existen en el los procesos judiciales o en el arbitraje. La ley considera crucial la flexibilidad de adaptar el proceso a las circunstancias de cada caso y a los deseos de las partes.

A los ojos de los negociadores de la ley, cuya inmensa mayoría fue de abogados y no mediadores profesionales, la preocupación más importante de las partes en lo que respecta a la conciliación era tener la certeza de que lo que se haya declarado o admitido durante el procedimiento no se utilizaría como prueba en su contra en otro procedimiento. Se consideró que con una solución contractual no se podía lograr ese objetivo, por lo que varios de los artículos de la ley desarrollaron reglas, generalmente sujetas a la voluntad de las partes, en cuestiones como el papel del conciliador en actuaciones judiciales o arbitrales subsiguientes, el proceso de nombramiento de conciliadores, los principios amplios aplicables al procedimiento conciliatorio, confidencialidad de la información y la ejecutoriedad del acuerdo de transacción.

\section{La ley modelo como instrumento de uniformidad}

Entre los objetivos de la ley modelo se identifica el fomentar el recurso a la conciliación, el ofrecer más previsibilidad y mayor certeza en su uso para promover la economía y la eficiencia en el comercio internacional. Este objetivo requiere propiciar uniformidad ante las prácticas disímiles entre los países y de diversas leyes en un mismo país, que siguen criterios diferentes en cuanto a la confidencialidad y a los privilegios probatorios y sus excepciones. La uniformidad contribuye a dar una mayor integridad y certeza al proceso conciliatorio y resulta aún más beneficiosa en los casos de conciliación por conducto de la internet, en que puede ocurrir que no esté claro el derecho aplicable. 


\section{La ley modelo como instrumento de armonización legislativa}

Por ley modelo se entiende todo texto legal que se recomienda a los Estados para su incorporación al derecho interno. Se anticipa que al incorporar el texto de la ley modelo a su derecho interno, es posible que el Estado desee modificar o suprimir alguna de sus disposiciones. Sin embargo, dichos cambios al tiempo que permiten flexibilidad no deben evitar un cierto grado de uniformidad, armonización y de certidumbre común a todos los Estados. Por ello, se recomienda procurar introducir el menor número posible de cambios al incorporar el régimen de la ley modelo al derecho interno, y se ha de procurar que todo cambio introducido sea compatible con los principios básicos de la ley modelo. Se persiguen regímenes internos transparentes y conocidos para las partes nacionales y extranjeras.

\section{5. Ámbito de aplicación}

Al preparar el proyecto de ley modelo se adoptó una noción amplia de la conciliación, que cabría designar también por términos como los de "mediación", "vía alternativa para la solución de una controversia", "dictamen neutral" y expresiones similares. Los negociadores pensaron que la ley modelo sea aplicable a la más amplia variedad posible de controversias comerciales internacionales, y que se pudiera ampliar en su alcance a las controversias comerciales internas e incluso a controversias no comerciales. La ley modelo, en consecuencia, podría ser incorporada al derecho interno como una ley general sobre conciliación o como parte de un régimen más amplio para la solución de las controversias.

\section{ESTRUCTURA DE LA LEY MODELO}

La ley modelo contiene definiciones, procedimientos y directrices para que las partes retengan el control sobre el procedimiento y su resultado.

Idealmente, no requeriría reglas jurídicas un procedimiento de negociación facilitada por una tercera para que las partes decidan por sí mismas su controversia (conciliación). Sin embargo, en aras de la uniformidad y armonización de reglas jurídicas para la conciliación — percibidas 
como una necesidad lógica del pensamiento jurídico - se optó por un mínimo de reglas posibles.

\section{Artículo 1. Ámbito de aplicación y definiciones}

Se entiende por conciliación todo procedimiento en el que las partes soliciten asistencia de un tercero o terceros para llegar a un arreglo amistoso. No importa si dicho procedimiento es designado como mediación o algún otro de sentido equivalente. El conciliador no está facultado para imponer una solución

La ley se aplica a la conciliación comercial internacional, aunque los estados pueden incorporarla a su derecho interno para hacerla aplicable a cualquier tipo de conciliaciones tanto nacionales como internacionales

El término conciliador se refiere a conciliador o conciliadores. El término conciliación busca incluir todos los términos que se refieren a un proceso donde un tercero asiste a las partes y pretende elimina las confusiones producidas por la divergencia conceptual de las legislaciones al denominar el proceso de conciliación con diversas expresiones. Se brinda la posibilidad a las partes de elegir utilizar la ley.

\section{Artículo 2. Interpretación}

Para la interpretación de la ley, deberá tomarse en cuenta la finalidad de la ley de promover la uniformidad de su aplicación y la observancia de su buena fe.

Las cuestiones que no estén expresamente resueltas en la ley deberán resolverse conforme a los principios generales en los que se inspira.

Establece un mecanismo de interpretación de la ley conforme a sus principios de origen internacional, búsqueda de uniformidad y principio de buena fe.

\section{Artículo 3. Modificación mediante acuerdo}

Las partes están facultadas para excluir o modificar cualquiera de las disposiciones de la ley.

Así, las partes tienen toda la flexibilidad para modificar la ley. Habrá que desaprender la creencia de que reglas definitivas son necesarias para el arreglo de conflictos legales 


\section{Artículo 4. Inicio del procedimiento de conciliación}

Las partes deciden el día de inicio de la conciliación.

Si la parte invitada a la conciliación no responde en un plazo de 30 días a partir de la fecha en la que se envió la invitación se tendrá por entendido que rechaza la oferta de conciliación.

De esta manera se establece un criterio para establecer cuando se inicia la conciliación.

\section{Artículo 5. Número y designación de los conciliadores}

Las partes decidirán el número de conciliadores

Las partes designarán al conciliador a excepción que se haya convenido un procedimiento distinto para su designación.

Las partes podrán solicitar asistencia de una institución o persona para la designación de los conciliadores.

La persona a la que se le comunique su posible nombramiento como conciliador deberá comunicar cualquier circunstancia que pueda dar lugar a dudas de su imparcialidad o independencia.

Se consagra la libertad para determinar número de conciliadores sin sujetarse a listas previas y se faculta a las partes para pedir asistencia a instituciones privadas o públicas para sugerir o designar conciliadores.

\section{Artículo 6. Sustanciación de la conciliación}

Las partes determinarán la forma en la que sustanciará la conciliación.

De no haber acuerdo, el conciliador podrá sustanciar el procedimiento conciliatorio del modo que estime adecuado.

El conciliador deberá procurar un tratamiento equitativo

El conciliador podrá presentar propuestas en cualquier etapa del procedimiento.

Se faculta a las partes para definir la sustanciación de la conciliación $\mathrm{y}$ al conciliador para proponer soluciones durante el proceso.

\section{Artículo 7. Comunicación entre el conciliador y las partes}

El conciliador podrá reunirse o comunicarse con las partes conjuntamente o por separado con cada una de ellas. 
Así, expresamente se faculta al conciliador para reunirse con las partes conjunta o separadamente según considere necesario.

\section{Artículo 8. Revelación de la información}

El conciliador, si recibe información de la controversia por una de las partes, podrá comunicarla a la otra parte, a excepción que la parte que da la información exprese su voluntad de mantenerlo como confidencial.

Se reconoce la discrecionalidad y buen juicio del conciliador para utilizar la información que le proporcionen las partes.

\section{Artículo 9. Confidencialidad}

Toda la información relativa al procedimiento conciliatorio deberá considerarse como confidencial a menos que las partes convengan otra cosa, o que su divulgación esté prescrita por ley.

El principio de confidencialidad es la regla para toda la información en la conciliación.

\section{Artículo 10. Admisibilidad de pruebas en otros procedimientos}

Ninguna persona que haya participado en la conciliación podrá presentar pruebas o rendir testimonio en un procedimiento arbitral o judicial, sin importar la forma que revistan la información.

En caso de que la información se presentase como prueba en algún tribunal arbitral, tribunal de justicia o cualquier otra autoridad pública, deberá ser considerada como inadmisible.

Se asegura a las partes de la confidencialidad de la información utilizada durante la conciliación.

\section{Artículo 11. Terminación del procedimiento de conciliación}

El procedimiento se dará por terminado:

a) En caso de arreglo conciliatorio

b) Si el conciliador presenta un documento con previa consulta a las partes en el que manifieste que no hay lugar a que siga intentándose la conciliación

c) Si las partes convienen dar por terminado el proceso

d) Si una de las partes decide terminar el proceso 
En congruencia con la libertad para iniciar una conciliación, se faculta a las partes para decidir la terminación del proceso de conciliación en cualquier momento.

\section{Artículo 12. El conciliador como árbitro}

Salvo acuerdo contrario de las partes, el conciliador no podrá actuar como árbitro en una controversia que haya sido o es objeto del procedimiento conciliatorio.

Se faculta a las partes para decidir que el conciliador funja como árbitro en caso de no llegar a un arreglo

\section{Artículo 13. Recurso a procedimientos arbitrales o judiciales}

El inicio de un procedimiento arbitral o judicial no constituirá, en si mismo, una renuncia al acuerdo previo de recurrir a la conciliación ni a la terminación de ésta.

Ofrece la posibilidad de tener un procedimiento de conciliación antes o después de un procedimiento arbitral o judicial.

\section{Artículo 14. Ejecutoriedad del acuerdo de transacción}

En caso de que las partes lleguen a un acuerdo por el que se resuelva la controversia, dicho acuerdo será vinculante y susceptible de ejecución.

La legislación de cada país determinará la forma jurídica o procedimiento para otorgar al acuerdo su carácter vinculante y susceptible de ejecución.

Este artículo mereció la más amplia discusión puesto que se refiere quizás al tema que más preocupa a un abogado tradicional, que se preocupa por la posible ejecución de sentencias o laudos. Por ello, resumiré las discusiones que hubo al respecto. ${ }^{21}$

El punto de partida era la opinión de profesionales del derecho de que la vía de la conciliación ganaría adeptos si se dotara al arreglo con-

21 Referencias a documentos de la CNUDMI relativos al artículo 14 en Documentos Oficiales de la Asamblea General, quincuagésimo séptimo periodo de sesiones, Suplemento núm. 17 (A/57/17), 119 a 126 y 172; A/CN.9/514, 77 a 81; A/CN.9/506, 38 a 48 y 133 a 139; A/CN.9/ WG.II/WP.115, observaciones 45 a 49; A/CN.9/487, 153 a 159; A/CN.9/WG.II/WP.110, 105 a 112 ; A/CN.9/WG.II/WP.113/Add.1, nota 39; A/CN.9/485, párr. 159; A/CN.9/468, 38 a 40; A/CN.9/ WG.II/WP.108, 16 y 34 a 42; A/CN.9/460, 16 a 18. 
certado en el curso de la conciliación de un régimen de ejecución ágil o de una fuerza ejecutoria idéntica o similar a la de un laudo arbitral. ${ }^{22}$

El texto adoptado constituyó el mínimo común denominador entre los diversos sistemas jurídicos. El interés era que los acuerdos de transacción debían ejecutarse con facilidad y rapidez. Sin embargo, se reconoció que los métodos para agilizar la ejecución diferían enormemente de un ordenamiento jurídico a otro y dependían de tecnicismos propios del derecho procesal interno que no se prestaban fácilmente a la armonización por medio de legislación uniforme.

La cuestión de la ejecutoriedad, las excepciones a la ejecutoriedad y la designación de los tribunales (u otras autoridades de las cuales se pudiera recabar la ejecución de un acuerdo de transacción) quedan supeditadas al derecho interno aplicable o a disposiciones de la ley por la que se promulgue el régimen de la ley modelo.

En ningún sentido se buscó impedir que las leyes del Estado impusieran requisitos de forma, como el requisito de firma o de una constancia por escrito, cuando ese requisito se considerara esencial.

En algunos países no se ha previsto un régimen especial para regular la ejecutoriedad de esos arreglos, sino que se les aplica el mismo régimen que se aplicaría a cualquier contrato concertado entre las partes. Esta interpretación, que asimila su ejecutoriedad a la de un contrato, se ha recogido en algunas leyes relativas a la conciliación. ${ }^{23}$

En otros países se permite a las partes que han resuelto una controversia por la vía de la conciliación designar un árbitro especialmente para que dicte un laudo basado en el acuerdo de transacción concertado entre ellas. Dicha práctica existe en Hungría y en la República de Corea. En Hungría, el capítulo 39 de la Ley LXXI, de 8 de noviembre de 1994, dispone que:

a) Si durante el procedimiento arbitral las partes llegan a un arreglo, el tribunal arbitral dictará un laudo para dar por terminado el procedimiento.

b) A solicitud de las partes, el tribunal arbitral dejará constancia del arreglo mediante un laudo redactado en los términos convenidos por las partes, siempre y cuando considere que ese arreglo está en consonancia con la ley aplicable. 
c) Un laudo arbitral redactado en los términos convenidos por las partes tiene el mismo efecto que cualquier otro laudo dictado por el tribunal arbitral.

En la República de Corea el régimen del arbitraje no contiene disposiciones sobre la conciliación, pero se recurre ampliamente a la vía de la conciliación o mediación (véase el Reglamento de Arbitraje Comercial de la Junta de Arbitraje Comercial de Corea, enmendado el 14 de diciembre de 1993). En el párrafo 3 del artículo 18 se dispone que, si la conciliación prospera, se considerara que el conciliador es el árbitro designado en virtud del acuerdo de las partes y que el arreglo al que se ha llegado será tratado como un laudo en los términos convenidos por las partes.

En China la conciliación puede estar a cargo de un tribunal arbitral, y la legislación dispone que, si el procedimiento da lugar a un acuerdo de transacción, el tribunal arbitral dejará constancia por escrito de éste o dictará un laudo arbitral de conformidad con el acuerdo de transacción. La constancia por escrito de la conciliación y el laudo arbitral dictado por escrito tendrán igual validez y efecto jurídicos.

En algunos ordenamientos, el valor de un acuerdo de transacción depende de si la conciliación ha tenido lugar en el marco del sistema judicial y de si se han entablado acciones judiciales respecto de la controversia. Por ejemplo, la legislación australiana dispone que los acuerdos de transacción concertados en procedimientos conciliatorios ajenos a la esfera judicial no pueden registrarse en los tribunales, a menos que haya procedimientos judiciales en curso, en tanto que en el caso de los procedimientos conciliatorios concertados en un marco judicial, el tribunal puede dictar órdenes basadas en el acuerdo de transacción que, como tales, tienen fuerza de ley y son ejecutables. ${ }^{24}$

En otros países se ha previsto una vía ejecutoria sumaria en el supuesto de que las partes y sus asesores letrados firmen un arreglo de transacción que contenga una declaración por la que se faculte a las partes para recabar la ejecución sumaria de su acuerdo. Asimismo, es posible que se haya previsto la ejecución sumaria de un arreglo que haya sido, por ejemplo, certificado por notario o refrendado por un juez.

En Bermudas se dispone que si las partes en un acuerdo de arbitraje que prevea el nombramiento de un conciliador resuelven sus diferencias y firman un acuerdo en que se detallen las condiciones del arreglo, el 
acuerdo de transacción será tratado, a efectos de su ejecución, como un laudo en un acuerdo de arbitraje y, con el consentimiento del tribunal o de un juez del tribunal, podrá ejecutarse del mismo modo que un fallo o un mandamiento al mismo efecto y, si se autoriza expresamente, se podrá dictar un fallo en los términos del acuerdo (Arbitration Act, 1986).

De manera análoga, en la India todo acuerdo de transacción que hayan firmado las partes es definitivo y vinculante para éstas y para las personas cuyos derechos estén supeditados a los de aquéllas, y tendrá la misma validez y el mismo efecto que un laudo arbitral (Arbitration and Conciliation Ordinance, 1996, artículos 73 y 74).

En Alemania, la Zivilprozessordnung (el Código de Procedimiento Civil) tiene en cuenta expresamente la práctica de llegar a una solución amistosa de una controversia durante el procedimiento de arbitraje disponiendo que el tribunal deje constancia del arreglo, a solicitud de las partes, mediante un laudo arbitral redactado en los términos convenidos, laudo éste que tendrá el mismo efecto que cualquier otro que se dicte sobre el fondo del asunto (Zivilprozessordnung, tomo X, sección 1053).

En otros países la ejecutoriedad de un acuerdo de transacción concertado durante el procedimiento conciliatorio dependerá de que el acuerdo se haya concertado en el marco de un arbitraje o de un acuerdo de arbitraje. Por ejemplo, en Hong Kong (China), cuando un procedimiento de conciliación prospera y las partes celebran un acuerdo de transacción por escrito (antes o durante un procedimiento de arbitraje), el Tribunal de Primera Instancia podrá ejecutar ese acuerdo como si fuera un laudo, siempre y cuando haya sido concertado por las partes en un acuerdo de arbitraje Arbitration Ordinance (cap. 341, enmendada con efecto a partir del 27 de junio de 1997).

Los países que no hayan incorporado a su derecho interno la Ley Modelo de la CNUDMI sobre Comercio Electrónico deberían considerar la posibilidad de incluir una disposición del tenor de los artículos 6 y 7 de ese instrumento con el objeto de eliminar los obstáculos que existan para utilizar más las comunicaciones electrónicas en la conciliación comercial internacional. El artículo 6 dispone en parte que, cuando la ley requiera que la información conste por escrito, ese requisito quedará satisfecho con un mensaje de datos si la información que éste contiene es accesible para su ulterior consulta. En el artículo 7 se dispone que cuando la ley requiera la firma de una persona, ese requisito quedará satisfecho en relación con un mensaje de datos: a) si se utiliza un método para 
identificar a esa persona y para indicar que esa persona aprueba la información que figura en el mensaje de datos; y $b$ ) si ese método es tan fiable como sea apropiado para los fines para los que se generó o comunicó el mensaje de datos, a la luz de todas las circunstancias del caso, incluido cualquier acuerdo pertinente. ${ }^{25}$

Conclusiones sobre la ley modelo sobre conciliación:

- Minimiza la judicialización de la conciliación

- Reafirma el principio de la voluntad suprema de las partes

- Fomenta y protege la confidencialidad de la información

- Uniforma el término conciliación

- Armoniza la práctica de conciliación en distintas legislaciones

- Facilita la solución de conflictos legales sin soluciones legales

\title{
IX. TEXTO DE LA LEY MODELO SOBRE CONCILIACIÓN COMERCIAL INTERNACIONAL
}

\begin{abstract}
Artículo 1. Ámbito de aplicación y definiciones
1) La presente Ley se aplicará a la conciliación comercial ${ }^{26}$ internacional. ${ }^{27}$

2) A los efectos de la presente Ley, el término "conciliador" podrá hacer referencia a un único conciliador o, en su caso, a dos o más conciliadores.

3) A los efectos de la presente Ley, se entenderá por "conciliación" todo procedimiento, designado por términos como los de conciliación, mediación o algún otro de sentido equivalente, en el que las partes soliciten a un tercero o terceros ("el conciliador"), que les preste asistencia
\end{abstract}

25 A/CN.9/506, 88. Publicación de las Naciones Unidas, núm. de venta S.99.V.4.

26 Debe darse una interpretación amplia al término "comercial" para que abarque las cuestiones que se plantean en todas las relaciones de índole comercial, contractuales o no. Las relaciones de carácter comercial comprenden, entre otras, las siguientes operaciones: cualquier operación comercial de suministro o intercambio de bienes o servicios, acuerdo de distribución, representación o mandato comercial, transferencia de créditos para su cobro (factoring), arrendamiento de bienes de equipo con opción de compra (leasing), construcción de obras, consultoría, ingeniería, concesión de licencias, inversión, financiación, banca, seguros, acuerdo o concesión de explotación, asociaciones de empresas y otras formas de cooperación industrial o comercial, transporte de mercancías o de pasajeros por vía aérea, marítima, férrea o por carretera.

27 Los Estados que deseen incorporar la presente ley modelo a su derecho interno para hacerla aplicable a los procedimientos de conciliación tanto nacionales como internacionales tal vez deseen enmendar el texto del modo siguiente: a) Suprímase la palabra "internacional" en el párrafo 1 del artículo 1 ; y b) Suprímanse los párrafos 4, 5 y 6 del artículo 1 . 
en su intento por llegar a un arreglo amistoso de una controversia que se derive de una relación contractual u otro tipo de relación jurídica o esté vinculada a ellas. El conciliador no estará facultado para imponer a las partes una solución de la controversia.

4) Una conciliación será internacional cuando:

a) Las partes en un acuerdo de conciliación tengan, en el momento de la celebración de ese acuerdo, sus establecimientos en Estados diferentes; o

b) El Estado en que las partes tengan sus establecimientos no sea:

i) El Estado en que deba cumplirse una parte sustancial de las obligaciones derivadas de la relación comercial; ni

ii) El Estado que esté más estrechamente vinculado al objeto de la controversia.

5) A los efectos del presente artículo:

a) Cuando alguna de las partes tenga más de un establecimiento, el establecimiento será el que guarde una relación más estrecha con el acuerdo de conciliación;

b) Cuando alguna de las partes no tenga ningún establecimiento, se tendrá en cuenta su residencia habitual.

6) La presente Ley también será aplicable a las conciliaciones comerciales cuando las partes convengan en que la conciliación es internacional o en que la presente Ley sea aplicable.

7) Las partes podrán convenir en que la presente Ley no sea aplicable.

8) Sin perjuicio de lo dispuesto en el párrafo 9), la presente Ley será aplicable independientemente de la razón por la cual se entable la conciliación, ya sea en virtud de un acuerdo concertado entre las partes antes o después de que surja la controversia, de una obligación establecida por ley o de instrucciones o indicaciones de un tribunal de justicia, tribunal arbitral o una entidad pública competente.

9) La presente Ley no será aplicable:

a) Cuando un juez o un árbitro, en el curso de un procedimiento judicial o arbitral, trate de facilitar la concertación de un arreglo entre las partes; $\mathrm{y}$

b) ...

Artículo 2. Interpretación

1) En la interpretación de la presente Ley habrán de tenerse en cuenta su origen internacional así como la necesidad de promover la uniformidad de su aplicación y la observancia de la buena fe.

2) Las cuestiones relativas a las materias que se rijan por la presente Ley y que no estén expresamente resueltas en ella se dirimirán de conformidad con los principios generales en que ella se inspira. 
Artículo 3. Modificación mediante acuerdo

Sin perjuicio de lo dispuesto en el artículo 2 y en el párrafo 3 del artículo 7, las partes podrán convenir en excluir o modificar cualquiera de las disposiciones de la presente Ley.

Artículo 4. Inicio del procedimiento de conciliación ${ }^{28}$

1) El procedimiento de conciliación relativo a una determinada controversia dará comienzo el día en que las partes acuerden iniciarlo.

2) La parte que haya invitado a otra a entablar un procedimiento de conciliación y no reciba de esta última una aceptación de la invitación en el plazo de 30 días a partir de la fecha en que envió la invitación o en cualquier otro plazo fijado en ella, podrá considerar que la otra parte ha rechazado su oferta de conciliación.

Artículo 5. Número y designación de conciliadores

1) El conciliador será uno solo, a menos que las partes acuerden que ha de haber dos o más.

2) Las partes tratarán de ponerse de acuerdo para designar al conciliador o los conciliadores, a menos que se haya convenido en un procedimiento diferente para su designación.

3) Las partes podrán recabar la asistencia de una institución o persona para la designación de los conciliadores. En particular:

a) Las partes podrán solicitar a tal institución o persona que les recomiende personas idóneas para desempeñar la función de conciliador; o

b) Las partes podrán convenir en que el nombramiento de uno o más conciliadores sea efectuado directamente por dicha institución o persona.

4) Al formular recomendaciones o efectuar nombramientos de personas para el cargo de conciliador, la institución o persona tendrá en cuenta las consideraciones que puedan garantizar el nombramiento de un conciliador independiente e imparcial y, en su caso, tendrá en cuenta la conveniencia de nombrar un conciliador de nacionalidad distinta a las nacionalidades de las partes.

5) La persona a quien se comunique su posible nombramiento como conciliador deberá revelar todas las circunstancias que puedan dar lugar a dudas justificadas acerca de su imparcialidad o independencia. El conciliador, desde el momento de su nombramiento y durante todo el

28 Los Estados que deseen adoptar una disposición relativa a la prescripción podrían incorporar en su respectiva ley el siguiente artículo: Artículo X. Suspensión del plazo de prescripción: 1) Cuando se inicie el procedimiento de conciliación dejará de correr el plazo de prescripción del asunto objeto de la conciliación, 2) Cuando el procedimiento de conciliación concluya sin llegarse a un arreglo, el plazo de prescripción se reanudará a partir del momento en que concluyera sin arreglo el procedimiento de conciliación. 
procedimiento conciliatorio, revelará sin demora tales circunstancias a las partes, a menos que ya les haya informado de ellas.

Artículo 6. Sustanciación de la conciliación

1) Las partes podrán determinar, por remisión a algún reglamento o por alguna otra vía, la forma en que se sustanciará la conciliación.

2) De no haber acuerdo al respecto, el conciliador podrá sustanciar el procedimiento conciliatorio del modo que estime adecuado, teniendo en cuenta las circunstancias del caso, los deseos que expresen las partes y la necesidad de lograr un rápido arreglo de la controversia.

3) En cualquier caso, el conciliador procurará dar a las partes un tratamiento equitativo, teniendo en cuenta las circunstancias del caso.

4) El conciliador podrá proceder, en cualquier etapa del procedimiento conciliatorio, a presentar propuestas para un arreglo de la controversia.

Artículo 7. Comunicación entre el conciliador y las partes

El conciliador podrá reunirse o comunicarse con las partes conjuntamente o con cada una de ellas por separado.

Artículo 8. Revelación de información

El conciliador, si recibe de una de las partes información relativa a la controversia, podrá revelar el contenido de esa información a la otra parte. No obstante, el conciliador no podrá revelar a ninguna de las otras partes la información que reciba de esa parte si ésta pone la condición expresa de que se mantenga confidencial.

Artículo 9. Confidencialidad

A menos que las partes convengan otra cosa, toda información relativa al procedimiento conciliatorio deberá considerarse confidencial, salvo que su divulgación esté prescrita por ley o que sea necesaria a efectos de cumplimiento o ejecución de un acuerdo de transacción.

Artículo 10. Admisibilidad de pruebas en otros procedimientos

1) Las partes en el procedimiento conciliatorio, el conciliador y los terceros, incluidos los que participen en la tramitación del procedimiento de conciliación, no harán valer ni presentarán pruebas, ni rendirán testimonio en un procedimiento arbitral, judicial o de índole similar en relación con:

a) La invitación de una de las partes a entablar un procedimiento de conciliación o el hecho de que una las partes esté dispuesta a participar en un procedimiento conciliatorio;

b) Las opiniones expresadas o las sugerencias formuladas por una de las partes en la conciliación respecto de un posible arreglo de la controversia;

c) Las declaraciones efectuadas o los hechos reconocidos por alguna de las partes en el curso del procedimiento conciliatorio;

d) Las propuestas presentadas por el conciliador; 
e) El hecho de que una de las partes se haya declarado dispuesta a aceptar un arreglo propuesto por el conciliador;

f) Cualquier documento preparado únicamente para los fines del procedimiento conciliatorio.

2) El párrafo 1) del presente artículo será aplicable cualquiera que sea la forma que revistan la información o las pruebas mencionadas en dicho párrafo.

3) Ningún tribunal arbitral, tribunal de justicia ni cualquier otra autoridad pública competente podrá revelar la información a que se hace referencia en el párrafo 1) del presente artículo y, si esa información se presentase como prueba en contravención del párrafo 1) del presente artículo, dicha prueba no se considerará admisible. No obstante, esa información podrá revelarse o admitirse como prueba en la medida en que lo prescriba la ley o en que sea necesario a efectos de cumplimiento o ejecución de un acuerdo de transacción.

4) Las disposiciones de los párrafos 1), 2) y 3) del presente artículo serán aplicables independientemente de que el procedimiento arbitral, judicial o de índole similar se refiera a la controversia que sea o haya sido objeto del procedimiento conciliatorio.

5) Sin perjuicio de las limitaciones enunciadas en el párrafo 1) del presente artículo, ninguna prueba que sea admisible en un procedimiento arbitral, judicial o de índole similar dejará de serlo por el hecho de haber sido utilizada en un procedimiento de conciliación.

Artículo 11. Terminación del procedimiento de conciliación

El procedimiento de conciliación se dará por terminado:

a) Al concertar las partes un arreglo conciliatorio, en la fecha de ese arreglo;

b) Al efectuar el conciliador, previa consulta con las partes, una declaración en la que se haga constar que ya no ha lugar a que siga intentándose llegar a la conciliación, en la fecha de tal declaración;

c) Al hacer las partes al conciliador una declaración de que dan por terminado el procedimiento de conciliación, en la fecha de tal declaración; o

d) Al hacer una parte a la otra o las otras partes y al conciliador, si se hubiere designado, una declaración de que da por terminado el procedimiento de conciliación, en la fecha de tal declaración.

Artículo 12. El conciliador como árbitro

Salvo acuerdo en contrario de las partes, el conciliador no podrá actuar como árbitro en una controversia que haya sido o sea objeto del procedimiento conciliatorio ni en otra controversia que surja a raíz del mismo contrato o relación jurídica o de cualquier contrato o relación jurídica conexos. 
Artículo 13. Recurso a procedimientos arbitrales o judiciales

Cuando las partes hayan acordado recurrir a la conciliación y se hayan comprometido expresamente a no entablar, en un determinado plazo o mientras no se produzca cierto hecho, ningún procedimiento arbitral o judicial con relación a una controversia existente o futura, el tribunal arbitral o de justicia dará efecto a ese compromiso en tanto no se haya cumplido lo en él estipulado, salvo en la medida necesaria para la salvaguardia de los derechos que, a juicio de las partes, les correspondan. El inicio de tal procedimiento no constituirá, en sí mismo, una renuncia al acuerdo de recurrir a la conciliación ni la terminación de ésta.

Artículo 14. Ejecutabilidad del acuerdo de transacción ${ }^{29}$

Si las partes llegan a un acuerdo por el que se resuelva la controversia, dicho acuerdo será vinculante y ejecutable [los Estados promulgantes podrán incorporar una descripción del medio de ejecución de los acuerdos de transacción o remitirse a las disposiciones que rijan su ejecutoriedad].

\section{PROPUESTA PARA INCORPORAR LOS PRINCIPIOS DE LA LEY MODELO A LA LEGISLACIÓN MEXICANA}

José Luis Siqueiros, quien fue el dictaminador del texto original sometido al anuario, sugirió al autor adicionar una propuesta para incorporar la ley modelo a la legislación nacional. Entre ambos elaboraron la propuesta que se adiciona.

\section{1. ¿Por qué una Ley sobre Conciliación Comercial Internacional en México?}

México se ha distinguido en el foro internacional por su interés en propiciar medios alternativos para la resolución de controversias en el ámbito mercantil. La adopción, casi íntegra, de la Ley Modelo de la CNUDMI sobre Arbitraje Comercial Internacional, en el título cuarto, libro quinto, del Código de Comercio en 1992, vino a dar un impulso a ese mecanismo a nivel legislativo y a fortalecerlo en la jurisprudencia mexicana.

$29 \mathrm{Al}$ aplicar el procedimiento de ejecución de los acuerdos de transacción, el Estado promulgante podrá considerar la posibilidad de que dicho procedimiento sea imperativo. 
Si bien ha significado un cambio lento y no sin dificultades, el uso de la Ley de Arbitraje por el gremio jurídico, y su reconocimiento y aceptación por el Poder Judicial han avanzado. En México cada día se recurre más al arbitraje como forma de resolver controversias tanto nacionales como internacionales. Las escuelas principales de México ya tienen cursos de arbitraje.

México cuenta además con dos centros administradores de procedimientos arbitrales sólidos y que en los últimos tres años han recibido apoyo del Banco Interamericano de Desarrollo: El Centro de Arbitraje de México (CAM) y la Comisión de Conciliación y Arbitraje de la Canaco. En las estadísticas de la Cámara de Comercio Internacional, cada vez con mayor frecuencia, ciudades mexicanas son designadas sedes de arbitraje internacionales.

A una experiencia positiva y enriquecedora debemos sumar otra que tiene el mismo sentido. El desafío es incorporar la Ley Modelo sobre Conciliación Comercial Internacional a nuestro derecho interno. Se trata de un conjunto de principios que conducen a una vía alternativa para la solución de controversias en forma extrajudicial.

\section{Uniformidad}

La ley modelo respondería a la visión de contar con reglas jurídicas similares para la solución de conflictos legales internacionales mediante la conciliación en distintos países. Una ley modelo propicia uniformidad y genera certidumbre jurídica y confianza.

Reglas comunes para un manejo flexible de conflictos facilitan el intercambio de riqueza a los proveedores internacionales de servicios, a los comerciantes internacionales y a los inversionistas extranjeros.

Uno de los aspectos estrictamente iniciales que los abogados asesores de inversionistas extranjeros se preguntan es sobre la regulación en materia de solución alternativa de conflictos en el país: ¿Hay arbitraje comercial? ¿Hay conciliación comercial? ¿La regulación interna de estas figuras está adaptada a principios y corrientes internacionales? No contar con respuestas puede convertirse en una barrera comercial.

\section{Sistematización}

En México es necesaria una ley que desarrolle sistemáticamente el tema de la conciliación. La legislación mexicana la contempla de 
modo accesorio y con enfoques múltiples, a veces excluyentes y sin consistencia.

Sin proponer un exceso de normatividad, ya que la conciliación es de sí un instrumento de flexibilidad para una negociación facilitada que resuelva conflictos, el seguir los principios básicos que integran la ley modelo cubre un hueco sin necesidad de inventar el hilo negro, ya que la ley modelo es el resultado de un trabajo universal de expertos en la materia. Permitiría establecer un marco legal que estableciera los principios sobre los cuales los Estados podrían regular.

\section{Actualidad mundial}

A partir de los noventa, se ha generado una tendencia universal en legislaciones nacionales que han adoptado la conciliación como un medio alterno para resolver controversias legales. La conciliación ha sido fortalecida como un modo autónomo de solución de conflictos, como una obligación para resolver conflictos en la interpretación o ejecución de contratos, y como un pre-requisito para la competencia de tribunales en casos concretos.

La negociación de la ley modelo de conciliación se realizó en dos años (2000-2002), periodo excepcionalmente breve para los patrones habituales de Naciones Unidas para la negociación de instrumentos jurídicos.

En 2003, la Conferencia de Comisionados para Leyes Uniformes en los Estados Unidos de América adoptó la ley modelo de conciliación como artículo dos de la Ley Uniforme de Mediación de 2002. También Hungría y Croacia ya la incorporaron a su ley nacional.

\section{Actualidad nacional}

En los últimos años en México, el Poder Judicial Federal y los Poderes Judiciales de dieciocho Estados de la República han realizado diversas actividades de promoción de la mediación y han adoptado reglamentaciones para su uso en diversos Estados.

El Proyecto de Mediación en México se gestó en septiembre del 2001, cuando el LALIC-Consejo para las Iniciativas Jurídicas de Latinoamérica de la American Bar Association (ABA), la Sección de Resolu- 
ción de Controversias de la propia ABA y Freedom House iniciaron un proyecto para incrementar el uso de la mediación en México. ${ }^{30}$

El proyecto ha impactado en los poderes judiciales de Aguascalientes, Baja California Sur, Chihuahua, Coahuila, Colima, Distrito Federal, Guanajuato, Jalisco, Michoacán, Nayarit, Nuevo León, Oaxaca, Puebla, Querétaro, Quintana Roo, Sonora, Tabasco, Tamaulipas. En 2004 el Consejo de la Judicatura el Tribunal Superior de Justicia del Distrito Federal estableció un Centro de Justicia Alternativa que inició su operación con la mediación en asuntos familiares.

Este proyecto ha sido apoyado por instituciones como la Universidad Nacional Autónoma de México, la Universidad de Guadalajara, Universidad Iberoamericana, Instituto Tecnológico Autónomo de México, Suprema Corte de Justicia de la Nación, Centro de Mediación Notarial, Instituto Mexicano de la Mediación.

Abogados mexicanos han formado el Instituto de Mediación de México, el Instituto Nacional de Mediación, el Instituto Mexicano de Mediación y el Centro Mexicano de Mediación, el Centro de Mediación Notarial y el Centro Interdisciplinario para el Manejo de Conflictos, A. C.

La Cámara Nacional de Comercio de la Ciudad de México (Canaco) cuenta con un reglamento en materia de mediación que funciona adecuadamente y ayuda a promover su uso por comerciantes nacionales y extranjeros.

En los últimos dos años se han llevado a cabo exitosamente cuatro Congresos Nacionales de Mediación (Hermosillo, Distrito Federal, Monterrey y Toluca). El quinto se celebrará en noviembre de 2005 en Hermosillo. ${ }^{31}$

\section{6. ¿Una estrategia de acción?}

Dada la aparente naturaleza no partidista de la ley sobre conciliación, parece no necesario presentarla como un tema político para el apoyo de algún partido político.

Desde una perspectiva internacional, el Comité 2022 del NAFTA sugirió en 2003 a la Comisión de Comercio del TLCAN que ésta recomiende su aprobación a los países del TLCAN. 
En el ámbito nacional, para lograr que el Congreso de la Unión considere la adopción de una ley sobre conciliación se sugiere un programa múltiple de acercamiento y convencimiento a los secretarios de Relaciones Exteriores y de Economía, dentro del Poder Ejecutivo; a algunos diputados y algunos senadores del Poder Legislativo; y a algunos jueces y ministros dentro del Poder Judicial.

\section{Aspectos técnico jurídicos}

La conciliación-mediación como un mecanismo autocompositivo y previo al arbitraje o a los tribunales judiciales, tiene ya una larga tradición en México. El Código de Procedimientos Civiles del Distrito Federal (CPCDF) de 1932, todavía en vigor, establece en su artículo 272-A que, "una vez contestada la demanda, y en su caso la reconvención, el juez señalará de inmediato fecha y hora para la celebración de una audiencia previa y de conciliación dentro de los diez díaz siguientes". El mismo dispositivo indica que si asistieran (a la audiencia) las dos partes, el juez los "procederá a procurar la conciliación" que estará a cargo del conciliador adscrito al juzgado. Este último propondrá a las partes alternativas para la solución del litigio; si los interesados llegaran a un convenio (transacción) el juez deberá aprobarlo si procediera legalmente. Dicho pacto tendrá fuerza de cosa juzgada.

Si bien es cierto que el Código Federal de Procedimientos Civiles (CFPC) no contiene ninguna disposición en materia de conciliación (o de arbitraje), otras leyes federales en materia mercantil si la contemplan (Ley de Protección y Defensa al Usuario de Servicios Financieros, Ley Federal de Protección al Consumidor, Ley del Mercado de Valores, entre muchas otras).

La realidad, sin embargo, es que hasta ahora, el Código de Comercio no contempla la conciliación o la mediación como una vía autónoma o previa al procedimiento contencioso ante árbitros o tribunales.

Tratándose de un medio alternativo previo al arbitraje y en cierta forma vinculado al último en su propósito resolutivo extrajudicial, podría considerarse la inclusión de un nuevo capítulo dentro del título cuarto y que se denominara "De la conciliación y el arbitraje comercial". El (nuevo) capítulo I, sección I, contendría aquellas disposiciones más importantes de la ley modelo en materia de procedimientos de conciliación comercial. 
Los temas que incluiría el nuevo capítulo serían: ámbito de aplicación y definiciones, flexibilidad para su modificación, número y designación de los conciliadores, comunicaciones entre los conciliadores y conciliados, confidencialidad, el conciliador como árbitro, y ejecutoriedad del acuerdo de transacción. 